\title{
BİST Şehir Endekslerinin Risk-Getiri Analizi Üzerine Bir İnceleme*
}

\author{
Ali BAYRAKDAROĞLU** \\ Yusuf TEPELI $\dot{I}^{* * *}$
}

\section{ÖZET}

Bu çalışma BIST'te faaliyet gösteren şehir endekslerinin risk-getiri açısından dengede olup olmadığ üzerine motive edilmiştir. Diğer çalışmalardan farklı olarak bu çalışmada finansal varlık pazar doğrusu kullantlarak risk-getiri dengesi incelenmiştir. Araştırma kapsamında BIST'te işlem gören 12 şehir endeksinin 2012-2017 dönemine ait ortalama getirileri, beta ve ĕgim beta değerleri ile risksiz faiz oranı kullanılmıştır. Yapılan analizler sonucunda şehir endekslerinden XSKON, XSIST, XSIZZM, XSDNZ, XSANK, XSANT, XSBAL endekslerinin aşırl, XSTKR, XSBUR, XSKOC, XSADA, XSKAY endekslerinin ise düşük değerlenmiş olduğu tespit edilmiştir. Bu bakımdan çalışmada, şehir endekslerinin aşırt ve düşük olarak belirlenen getiri düzeyleri, BIST 100 Endeksiyle karşılaştırılarak, yatırımcılara yatırım kararı sürecinde değerlendirme yapabilme olanağı sunmaktadır.

Anahtar Kelimeler: Şehir Endeksleri, Risk-Getiri Analizi, BIST 100 Endeksi

JEL Sinıflandırması: G11, G15, G32

\section{An Investigation on the BIST City Indexes in the Context of Risk-Return Analysis}

\section{ABSTRACT}

This study has been motivated by the fact that the city indexes operating in the BIST are balanced in terms of risk-return. Unlike other studies, risk-return balance has been examined in this study using the financial asset market line. The average return, beta and slope beta values and the risk-free interest rate for the 2012-2017 period of 12 city indexes traded in the BIST were used. As a result of the analyzes made, it has been determined that XSKON, XSIST, XSISM, XSDNZ, XSANK, XSANT, XSBAL indices are overvalued, XSTKR, XSBUR, XSKOC, $X S A D A$ and XSKAY indices are underestimated in city indices. In this respect, the study offers the possibility of making an assessment in terms of investor investment decision making process by comparing the high and low returns of city indexes with the BIST 100 Index.

Keywords: City Indexes, Risk-Return Analysis, BIST 100 Index

Jel Classification: G11, G15, G32

\footnotetext{
* 2018 yılında düzenlenen IV. Uluslararası Sosyal, Beşeri ve İdari Bilimler Sempozyumu'nda özet metin olarak sunulmuştur.

** Doç.Dr. Ali BAYRAKDAROĞLU, Muğla Sıtkı Koçman Üniversitesi, İktisadi ve İdari Bilimler Fakültesi, abayrakdaroglu@mu.edu.tr.

*** Araş.Gör. Yusuf TEPELİ, Muğla Sıtkı Koçman Üniversitesi, İktisadi ve İdari Bilimler Fakültesi, yusuftepeli@mu.edu.tr, 02522115062.
} 


\section{GİRiş}

Finansal piyasalarda endeksler; yatırım araçlarının fiyatlarında, maliyetlerinde ve satış performanslarında belirli bir zamandaki oransal değişimi ölçen göstergeler olarak tanımlanmaktadır (Aydemir, 2017). Bu açıdan bakıldığında endeksler, fiyat-maliyet ve satış performansındaki karmaşık sürecin tek bir değere, çoğu zaman da bir rakama indirgenmesini sağlamaktadır (Bayraktar, 2012: 90). Sermaye piyasalarında, özellikle borsada, endeks önemli bir gösterge olarak kabul edilmektedir (Fontanills, 2005: 416). Bu gösterge, finansal yatırımcıya sahip olduğu yatırım araçlarından oluşan portföyün veya varlığın getirisini alternatif yatırım araçlarına kıyaslama imkânı vermektedir (Akel, 2014: 47). Finansal bir varlığın zaman sürecindeki fiyat-maliyet-satış bilgisinin tarihsel olarak değişimini gösteren endeksler, rasyonel yatırımcılar için önemli bir sinyal niteliğini taşımaktadır (Mazgit, 2013:225).

Yatırımcılar tarafından sermaye piyasalarında, "gösterge" ve "yatırım" amaçlı birçok endeks kullanılmakta ve bunların başında da pay senedi endeksleri gelmektedir. Diğer bir ifadeyle endekslerin gösterge ve yatırım fonksiyonu olduğu söylenebilir. Gösterge fonksiyonu; bu endekslerin pay senetlerinin fiyatlarını baz alarak piyasa performansını yansıtmasından ileri gelmektedir. Yatırım fonksiyonu ise; 1990'l1 yıllardan sonra yatırımcının riski dağıtmak amacıyla tek bir finansal varlığa yatırım yapmaktansa bunların hepsinden oluşan, Markowitz'in ifade ettiği, piyasa portföyüne yatırım yapmayı ve riski minimize etmeyi amaçlamasından kaynaklanmaktadır. Genel olarak borsa yönetimlerince oluşturulan bu endeksler; uluslararası, ulusal, sektörel, bölgesel ve şehir bazında hesaplanabilmektedir ${ }^{1}$. Buradaki amaç; borsada işlem gören pay senetlerinin (şirketlerin) gruplar halinde ortak performanslarının ölçülmesidir (BİAŞ, 2013: 1). Dolayısıyla şehir bazında endekslerin oluşturulmasında, o şehirlerde faaliyet gösteren işletmelerin performanslarının ölçülmesi hedeflenmektedir (Bayramoğlu ve Pekkaya, 2010: 200). İlk olarak 2009 yılından bu yana Borsa İstanbul'da hesaplanmaya başlanan ve işlem gören şehir endekslerinin bugün itibariyle sayıs1 12'dir.

Şehir endeksleri; performans göstergesi niteliği taşıdığından, yatırımcıların finansal varlıklara ilişkin olarak yatırım kararlarını verme aşamasında oldukça etkin bir şekilde yararlanabileceği endekslerdir (Aşkın ve Büyüklü, 2014: 59-82). Bu çalışmada, rasyonel yatırımcının beklenen fayda teorisi kapsamında risk-getiri açısından popülaritesi oldukça yüksek olan şehir endeksleri incelenerek, finansal varlık pazar doğrusu (FVPD) yardımıyla yatırımcı için aşırı değerlenmiş ve düşük değerlenmiş olan şehir endekslerinin belirlenmesi amaçlanmıştır. Bu sayede sermaye piyasalarında yatırımcının şehir endekslerine nasıl yatırım kararı verebileceği gösterilmiştir. $\mathrm{Bu}$ doğrultuda çalışma dört bölümden oluşmaktadır. İlerleyen bölümlerde literatür incelenerek çalışmanın metodolojisi verilmiştir. Daha sonra veriler kapsamında yapılan analizler sonucunda araştırmanın bulgularına değinilerek son kısımda ise sonuç ve değerlendirme yapılmıştır.

\section{LITERATÜR TARAMASI}

Literatür incelendiğinde endekslerle ilgili yapılan çalışmaların büyük bir çoğunluğunun, endekslerin yönünü tahmin etmeye yönelik olduğu görülmüştür. Kim (2003),

\footnotetext{
${ }^{1}$ Temettü, halka arz ve kurumsal yönetim gibi alanlara yönelik olarak da endeksler hesaplanmaktadır (www.bist.com.tr).
} 
Diler (2003), Altay ve Satman (2005), Boyacıoğlu ve Avc1 (2011) ile Özdemir vd. (2011) çalışmalarında Yapay Sinir Ağları, Destek Vektör Makineleri ve ANFIS gibi yöntemleri kullanarak farklı başarı yüzdeleriyle endekslerin yönünü tahmin etmişlerdir. Diğer taraftan önde gelen uluslararası hisse senedi endekslerinin getirileri ile çeşitli yükselen ekonomi hisse senedi piyasası endeksleri arasındaki karşılıklı bağımlılık ve ilişki derecesini araştıran çalışmalarla (Masih ve Masih, 2001), gelişmiş ve yükselen piyasa ekonomileri arasında volatilite yayılma etkisini inceleyen çalışmalar (Liu ve Pan, 1997; Worthington ve Higgs, 2004; Bierne vd., 2009) da görülmektedir. Bu çalışmalar neticesinde yükselen hisse senedi piyasalarının genellikle ABD, İngiltere ve Japonya gibi hisse senedi piyasalarından etkilendiği ve gelişmiş ülke hisse senedi piyasalarından gelişmekte olan piyasalara yönelik anlamlı yayılma etkileri tespit edilmiştir.

Belirli bir endeks kapsamında olmak, endeks için tanımlanan belirli niteliklere sahip olmayı ifade ettiğinden, herhangi bir endekse dahil olmanın hisse senedi göstergeleri üzerinde etkileri olmaktadır. Nitekim Bayraktar (2012) ve Mazgit (2013) çalışmalarında bu etkiyi incelemişlerdir. Bayraktar çalışmasında endekse dahil edilen veya endeksten çıkarılan hisse senetlerinin, değişiklik duyurusunun yapıldığı tarihlerde fiyat yükselişleri/düşüşlerle birlikte işlem hacminde ciddi artışlar tespit etmiştir. Mazgit ise çalışmasının sonucunda beklenenin aksine, BİST Temettü 25 Endeksi'nden çıkarılanlardan oluşturulan portföyün, eklenenlerden daha olumlu sonuçlar verdiğini belirlemiştir.

Türkiye sermaye piyasası için oldukça yeni olan ve mikro ölçekli analizler için önemli bir gösterge niteliği taşıyan şehir endeksleri üzerine kısıtlı çalışma mevcuttur. Bayramoğlu ve Pekkaya (2010) tarafından yapılan ilk çalışmada şehir endekslerinin öneminden bahsedilerek finans alanında kullanımı üzerinde durulmuştur. Aşkın ve Büyüklü (2014) çalışmalarında GARCH ve EGARCH spesifikasyonları ile haftanın günü anomalisini incelemişler ve Bursa şehir endeksinin ortalama getirilerinde pozitif pazartesi etkisinin görüldüğünü belirlemişlerdir. Şehir endeksleri, endeks kapsamına giren şehirlerin performanslarının karşılaştırılmasına da imkan vermektedir. $\mathrm{Bu}$ amaçla yapılan çalışmaların ilkinde Akel (2014), 12 şehir endeksinin günlük verilerini kullanarak Şubat 2014 itibariyle bu endekslerin borsa performanslarını değerlendirmiştir. Çalışmaya göre en yüksek günlük ortalama getiriyi Tekirdağ, en düşük günlük ortalama getiriyi ise Konya endeksinin sağladığı ayrıca Tekirdağ, Kocaeli, İzmir, Bursa ve İstanbul endekslerinin XU100 Endeksinden daha yüksek performans gösteren endeksler olduğunu belirtilmiştir. Bir diğer çalışmada ise Çakır (2016), şehir endekslerinin performanslarını, risklerini de dikkate alarak değerlendirmiş ve elde ettiği bulgular doğrultusunda, yatırımcıların performansları yüksek çıkan Tekirdağ, Bursa ve Kocaeli endekslerine yatırım yapabileceklerini belirtmiştir.

Literatürde borsa endeksleri ile çeşitli kapsamlarda yapılmış birçok çalışma olmasına rağmen, şehir endekslerine odaklanan yeterli düzeyde çalışmaya rastlanılmamıştır. Literatürde risk-getiri açısından birçok çalışma olmasına rağmen bu çalışmayla finansal varlık pazar doğrusunu kullanarak yatırımcının risk-getiri dengesi açısından ucuz veya pahalı olan şehir endekslerine yatırımı noktasında katkı sağlaması beklenmektedir. 


\section{VERİ SETİ VE METODOLOJİ}

Araştırmanın temel motivasyonu; borsada endeks yatırımcıları için risk-getiri dengesinin gözetilerek aşırı veya düşük değerlenmiş olan şehir endekslerinin belirlenmesinin yatırım kararlarında yol gösterici bir unsur olabileceğidir. Bu bağlamda test edilmek istenen temel durum araştırma kapsamı içinde herhangi zamanda risk-getiri açısından şehir endeksleri dengede olup olmadı̆̆ıdır. Diğer bir ifadeyle yatırımcının şehir endekslerine yatırım yaparak katlandığı riske göre bir getiri getirip getirmediği durumu araştırılmıştır.

Analiz kapsamındaki şehir endekslerinin risk-getiri açısından dengede olmadığı ve aşırı veya düşük değerlendiği durumda endeks yatırımcısı borsadaki yatııım kararını uzun veya kısa pozisyon almak şeklinde verebilecektir. İlgili dönem itibariyle yatırımcı aşırı değerlenmiş şehir endeksini pahalı bularak kısa pozisyona geçecek veya elinde yoksa hiç yatırım yapmayacak, diğer durumda ise yatırımcı düşük değerlenmiş bir şehir endeksinin ucuz olduğuna karar vererek portföyünde uzun pozisyon alacaktır. Dolayısıyla yatırımcı bu iki durumda da piyasayı yenebileceği yönünde aktif stratejiler uygulayacaktır. Diğer durumda endeks yatırımcısı için borsadaki şehir endekslerinin alınan riske karşılık elde edilen getiri açısından dengede olduğu kabul edilir. Dolayısıyla yatırımcının beklenen getirileri ile olması gereken getirilerinin aynı olduğu durumu geçerli olacaktır. Bu durum şehir endekslerinin riskgetiri açısından finansal varlık pazar doğrusu üzerinde yer aldığına işaret edecektir. Sonuç olarak, endeks yatırımcısı katlandığı risk kadar getiri elde edecektir. Bu bağlamda araştırmada kurgulanan model aşağıdaki gibidir;

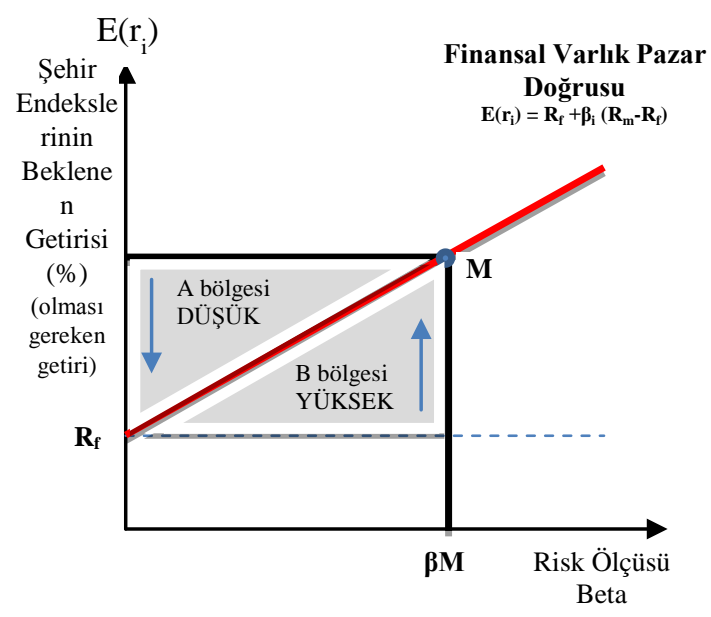

Şekil 1. Finansal Varlık Pazar Doğrusunda Şehir Endekslerinin Getirileri

Modelde finansal varlık pazar doğrusu kapsamında BİST 100 endeksinin (M) getirisi kıyaslama ölçütü alınarak, şehir endeksinin sağladığı beklenen getiri oranı $\mathrm{E}\left(\mathrm{r}_{\mathrm{i}}\right)$; beta katsayısı $\left(\beta_{i}\right)$ temelinde piyasa risk pirimi $\left(\mathrm{R}_{\mathrm{m}}-\mathrm{R}_{\mathrm{f}}\right)$ ve risksiz getiri oranı $\left(\mathrm{R}_{\mathrm{f}}\right)$ ile ilişkilendirerek elde edilmiştir. $E\left(r_{i}\right)$ olması gereken getiri olarak dikkate alınmış ve beta katsayısı ile karşılaş̧ırılarak ucuz veya pahalı ya da diğer bir ifade şekliyle düşük veya aşırı değerlenmiş̧ olup olmadığına karar verilmiş̧ir. $\mathrm{Bu}$ kapsamda kullanılan değişkenlere ait modelin matematiksel ifadesi $E\left(r_{i}\right)=R_{f}+\beta_{i}\left(R_{m}-R_{f}\right)$ şeklindedir. Araştırma kapsamında yer alan 
değişkenlere ait veri seti, Finnet Analiz Expert ${ }^{2}$ yazılım programından yararlanılarak oluşturulmuştur. Analizde test edilen şehir endeksleri Tablo 1'de verilmiştir.

Tablo 1. Şehir Endeksleri ve Endeksleri Oluşturan Şirketler*

\begin{tabular}{|c|c|c|c|c|c|}
\hline $\begin{array}{c}\text { Adana } \\
\text { (XSADA) }\end{array}$ & $\begin{array}{c}\text { Ankara } \\
\text { (XSANK) }\end{array}$ & $\begin{array}{l}\text { Antalya } \\
\text { (XSANT) }\end{array}$ & $\begin{array}{l}\text { Balıkesir } \\
\text { (XSBAL) }\end{array}$ & $\begin{array}{c}\text { Bursa } \\
\text { (XSBUR) }\end{array}$ & $\begin{array}{c}\text { Denizli } \\
\text { (XSDNZ) }\end{array}$ \\
\hline $\begin{array}{c}\text { 31.12.2008 } \\
\text { oluşturulma tarihi }\end{array}$ & $\begin{array}{c}\text { 31.12.2008 } \\
\text { oluşturulma tarihi }\end{array}$ & $\begin{array}{c}\text { 31.12.2008 } \\
\text { oluşturulma tarihi }\end{array}$ & $\begin{array}{c}\text { 31.12.2008 } \\
\text { oluşturulma tarihi }\end{array}$ & $\begin{array}{c}31.12 .2008 \\
\text { oluşturulma tarihi }\end{array}$ & $\begin{array}{c}\text { 06.07.2012 } \\
\text { oluşturulma tarihi }\end{array}$ \\
\hline SASA & KOZAL & TEKTU & KRSTAL & KARSN & DENCM \\
\hline ADNAC & OSTIM & MAALT & BNTAS & ZOREN & MNDRS \\
\hline BOSSA & ТTКОМ & UTPYA & BANVT & CEMTS & ACSEL \\
\hline Toplam 6 şirket & Toplam 15 şirket & Toplam 5 şirket & Toplam 4 şirket & Toplam 17 şirket & Toplam 4 şirket \\
\hline İstanbul & İzmir & Kayseri & Kocaeli & Konya & Tekirdağ \\
\hline (XSIST) & (XSIZM) & (XSKAY & (XSKOC) & (XSKON & (XSTKR) \\
\hline $\begin{array}{c}\text { 31.12.2008 } \\
\text { oluşturulma tarihi }\end{array}$ & $\begin{array}{c}\text { 31.12.2008 } \\
\text { oluşturulma tarihi }\end{array}$ & $\begin{array}{c}\text { 31.12.2008 } \\
\text { oluşturulma tarihi }\end{array}$ & $\begin{array}{c}\text { 31.12.2008 } \\
\text { oluşturulma tarihi }\end{array}$ & $\begin{array}{c}04.12 .2012 \\
\text { oluşturulma tarihi }\end{array}$ & $\begin{array}{c}\text { 31.12.2008 } \\
\text { oluşturulma tarihi }\end{array}$ \\
\hline THYAO & TUKAS & AYEN & POLHO & ITTFH & BRKSN \\
\hline GRSAY & PETKM & YATAS & ASUZU & KONYA & DEVA \\
\hline IEYHO & ALYAG & OYLUM & TUPRS & BERA & YUNSA \\
\hline Toplam 90 şirket & Toplam 27 şirket & Toplam 6 şirket & Toplam 19 şirket & Toplam 5 şirket & Toplam 3 şirket \\
\hline
\end{tabular}

*2018 Mart ayı itibariyle işlem hacmi en yüksek 3 şirketi göstermektedir.

Buna göre XSDNZ ve XSKON hariç diğer bütün şehir endeksleri 2008 yılında oluşturulmuştur. En fazla şirketi bünyesinde barındıran şehir endeksi doğal olarak XSIST'dir. Bunu 27 şirket ile XSIZM ve 19 şirket ile de XSKOC takip etmektedir. Tabloda her bir şehir endeksinde en çok işlem hacmine sahip ilk üç şirket yer almaktadır. Bu endeksler kapsamında yer alan şirketlerin tamamı Ek-1'de verilmiştir.

Beta katsayısı hesaplamalarında 31 Aralık 2012 ile 06 Aralık 2017 tarihleri arasındaki günlük veriler kullanılmıştır. Hesaplamalarda 732 gözlem dikkate alınmış ve her bir şehir endeksinin varyans ve kovaryans hesaplamaları yapılarak beta değerleri elde edilmiştir (Dağlı, 2004: 359-364). Ayrıca her bir şehir endeksinin pazar portföyü olarak kabul edilen BİST 100 endeksinin getirileri ile olan eğimi de hesaplanmış ve beta değerleri doğrulanmıştır. Risksiz faiz oranı ${ }^{3}$, modelde regresyon doğrusu kapsamında şehir endeksinin ortalama getirisi ile şehir endeksin beta değerinin kesme noktası olarak hesaplanmıştır (Karan, 2011: 218-219;

\footnotetext{
2 Finnet Analiz Expert, Türkiye sermaye piyasası araçlarına ilişkin, detaylı veri setlerinin, "Excel Ortamında" kullanılabilmesini ve raporlamalar yapılabilmesine imkân sağlayan, lisanslı finansal analiz programıdır. http://www.analizexpert.com/tr

${ }^{3}$ Bazı ampirik çalışmalarda 3 aylık hazine bonosunun üzerinde yazılı olan faiz oranı olarak dikkate alınmıştır (Akbulaev, Aliyeva, \& Ahmedova, 2016: 204)
} 
Gürsoy, 2012: 268-269). Daha sonraki süreçte şehir endeksinin sahip olması gereken beklenen getiri ile gerçekleşen getirileri beta değerleri kapsamında karşılaştırılarak, endeksin düşük veya aşırı değerlendiğine karar verilmiştir. Bu sonuçlara göre yatırımcılar her bir şehir endeksinin durumuna göre alım ve satım pozisyonlarını ayarlayabilecektir.

\section{BULGULAR VE TARTIŞMA}

Araştırma kapsamında öncelikle şehir endekslerinin ilgili dönemde her birinin ortalama getirileri hesaplanmıştır. 2012-2017 dönemi arasında elde edilen ortalama getiriler ve bunlara ait hesaplanan varyans-kovaryans değerleri ve bulunan beta değerleri aşağıda Tablo 2'de verilmiştir.

Tablo 2. Şehir Endekslerine Ait Ortalama Getiri ve Beta Değerlerinin Hesaplanması*

\begin{tabular}{|c|c|c|c|c|c|c|c|c|c|c|c|c|c|}
\hline Tarih & ADA & ANK & ANT & BUR & IST & IZM & KAY & KOC & TKR & BAL & DNZ & KON & XU100 \\
\hline 06.12 .2017 & $-3,32$ & 10,34 & $-4,48$ & 2,01 & 6,97 & 7,94 & 51,49 & 11,26 & $-0,19$ & $-5,03$ & $-10,04$ & 36,69 & 0,12 \\
\hline 30.11 .2017 & $-1,09$ & 14,52 & $-4,17$ & 2,17 & 8,19 & 10,20 & 51,21 & 18,47 & $-1,30$ & $-6,91$ & $-10,78$ & 30,53 & 2,86 \\
\hline 31.10 .2017 & $-12,83$ & 25,32 & 12,67 & 9,77 & 9,38 & 23,71 & 60,69 & 30,60 & 12,80 & 21,64 & $-3,60$ & 6,31 & 12,01 \\
\hline$\ldots$ & $\ldots$ & $\ldots$ & $\ldots$ & $\ldots$ & $\ldots$ & $\ldots$ & $\ldots$ & $\ldots$ & $\ldots$ & $\ldots$ & $\ldots$ & $\ldots$ & $\ldots$ \\
\hline 28.02 .2013 & 6,81 & 18,06 & 3,70 & 18,72 & 21,77 & 17,17 & 12,52 & 22,01 & 9,52 & $-5,55$ & 2,71 & 0,00 & 17,73 \\
\hline 31.01 .2013 & 10,98 & 9,07 & $-0,53$ & 15,80 & 17,99 & 18,47 & 3,27 & 14,32 & $-3,75$ & $-4,24$ & $-11,91$ & 0,00 & 15,97 \\
\hline 31.12 .2012 & 7,65 & 14,45 & $-7,07$ & 14,83 & 18,19 & 17,49 & 4,17 & 25,42 & 13,88 & $-10,61$ & $-10,13$ & 0,00 & 19,76 \\
\hline Ortalama Getiri & $\mathbf{1 0 , 5 7}$ & $\mathbf{6 , 4 3}$ & $\mathbf{2 , 3 6}$ & $\mathbf{9 , 1 1}$ & $\mathbf{4 , 4 4}$ & $\mathbf{6 , 0 0}$ & $\mathbf{1 7 , 2 3}$ & $\mathbf{9 , 4 5}$ & $\mathbf{3 , 9 5}$ & $\mathbf{6 , 3 3}$ & $\mathbf{5 , 2 8}$ & $\mathbf{0 , 5 8}$ & $\mathbf{4 , 3 4}$ \\
\hline Kovaryans & 149,11 & 130,8 & 149,3 & 91,81 & 107,1 & 123,3 & 150,9 & 127,5 & 35,79 & 180,6 & 128 & 76,7 & 135,7 \\
\hline 5 & 312,46 & 171,4 & 285,6 & 100,1 & 98,01 & 210 & 575 & 201 & 123,8 & 411,3 & 385,2 & 177,6 & 138 \\
\hline
\end{tabular}

Tablo 2 incelendiğinde ilgili dönemde pazar portföyü olarak kabul ettiğimiz BİST 100 endeksinin ortalama değeri 4,34'dür. Buna göre XSKAY şehir endeksi \%17,23 ile pazar portföyünün en üstünde bir getiri sağlayan şehir endeksi olmuştur. Bunu \%10,57 ile XSADA ve $\% 9,45^{\prime}$ lik getiri ile XSKOC takip etmektedir. Pazar portföyünün altında getiri sağlayan şehir endekslerinin sayısı 3'tür. En az getiri sağlayan şehir endeksi XSKON'dur. Görüldüğü üzere şehir endekslerinin getirileri pazar portföyünün getiri oranlarından oldukça yüksektir. Diğer bir ifadeyle şehir endekslerinin \%75'i BİST'ten daha fazla getiri sağlamıştır. Bu durum yatırımcı için karar verme noktasına önemli bir veri olarak kabul edilebilir. Bununla beraber beta değerlerine ${ }^{6}$ bakıldığında pazar portföyünün betasının teorik olarak 1 çıkması gerektiğinden hareketle şehir endekslerinin hepsinin pazar portföyü ile beraber hareket ettiği görülmektedir. Bütün değerler pozitif çıkmıştır. Eğim_beta değerleri dikkate alındığında XSADA, XSANT, XSKAY ve XSBAL şehir endeksleri pazardan daha hareketli olduğu piyasanın üstünde tepkiler verdiği görülmektedir (eğim_beta değerleri $>1$ olduğundan). Buna

${ }^{4} \sigma_{i, k}=\sum_{j=1}^{n} P_{j}\left[\left(R_{i j}-E\left(R_{i}\right)\right)\left(R_{k j}-E\left(R_{k}\right)\right)\right]$ burada $\sigma_{\mathrm{ik}} \mathrm{i}$ ve $\mathrm{k}$ varlıklarının getiri oranlarının kovaryansını, $\mathrm{P}_{\mathrm{j}} \mathrm{j}$ durumunun gerçekleşme olasılığını, $\mathrm{R}_{\mathrm{ij}} \mathrm{j}$

durumunun gerçekleşmesi halinde i varlığının getiri oranını, $R_{k j} j$ durumunun gerçekleşmesi halinde $k$ varlığının getiri oranını, $E\left(R_{i}\right) i$ varlığının beklenen getiri oranını ve $\mathrm{E}\left(\mathrm{R}_{\mathrm{k}}\right)$ ise k varlığının beklenen getiri oranını göstermektedir.

${ }^{5} \sigma_{i}^{2}=\sum_{j=1}^{n} P_{j}\left[\left(R_{i j}-E\left(R_{i}\right)\right]^{2}\right.$ burada $\sigma_{i}^{2}$ i varlığının varyansını, $P_{j} j$ durumunun gerçekleşme olasılığını, $E\left(R_{i}\right)$ i varlığının beklenen getiri oranını ve

$R_{i j}$ ise $\mathrm{j}$ durumunun gerçekleşmesi halinde i varlığının getiri oranını temsil etmektedir.

${ }^{6}$ Analizler kapsamında eğim_beta değerleri dikkate alınmıştır. 
karşın pazar portföyünde olan değişimlere en az tepkiyi ise XSTKR şehir endeksi vermektedir.

Beta katsayısının $\left(E\left(r_{i}\right)=R_{f}+\beta_{i}\left(R_{m}-R_{f}\right)\right)$ yapısına dayanılarak şehir endeksi ile pazar portföyünün getirileri arasındaki ilişkiyi belirlemede regresyon analizinden de yararlanılabilir. Çünkü beta katsayısı bu regresyon doğrusunun eğimidir. Şehir endeksinin getiri oranı ile pazar portföyünün getiri oranı arasındaki ilişkinin doğrusal olduğunu varsayarsak, şehir endeksinin getiri oranı endeks modeline dönüşür (Akbulaev, Aliyeva, \& Ahmedova, 2016: 204). Buna aynı zamanda varlığın "karakteristik doğrusu" da denilmektedir $\left(E\left(r_{i}\right)=\alpha_{i}+\beta_{i} R_{m}+\varepsilon_{i}\right)$. Buna göre FVPD denkleminde karakteristik doğru dikkate alındığında sabit terimin risksiz getiri oranı (Rf), doğrunun eğimi ise piyasa risk primidir (Altay, 2004: 83-90). Bu bağlamda şehir endekslerinin, finansal varlık pazar doğrusu kapsamında, beklenen getirilerinin hesaplanabilmesi ve karşılaştırmaların yapılabilmesi için $\mathrm{R}_{\mathrm{f}}$ değeri olarak her bir şehir endeksinin ortalama getirisi ile her bir şehir endeksin beta değerinin kesme noktası hesaplanmıştır. Bu kesme noktası $R_{\mathrm{f}}$ değerini vermektedir (Korkmaz ve Pekkaya, 2005: 566). $\mathrm{Bu}$ doğrultuda aynı mantık çerçevesinde FVPD'nin eğimi, piyasa risk pirimi olarak hesaplanmıştır. Her iki hesaplamada Tablo-3 Panel A ve B'de gösterilmiştir. Hesaplamalar Excel $^{7}$ paket programının "eğim" ve "kesmenoktası" fonksiyonları ile hesaplanmıştır.

Tablo 3. Şehir Endekslerine Ait $\mathrm{R}_{\mathrm{f}}$, Piyasa Risk Primi ve Beklenen Getiri Hesaplamaları

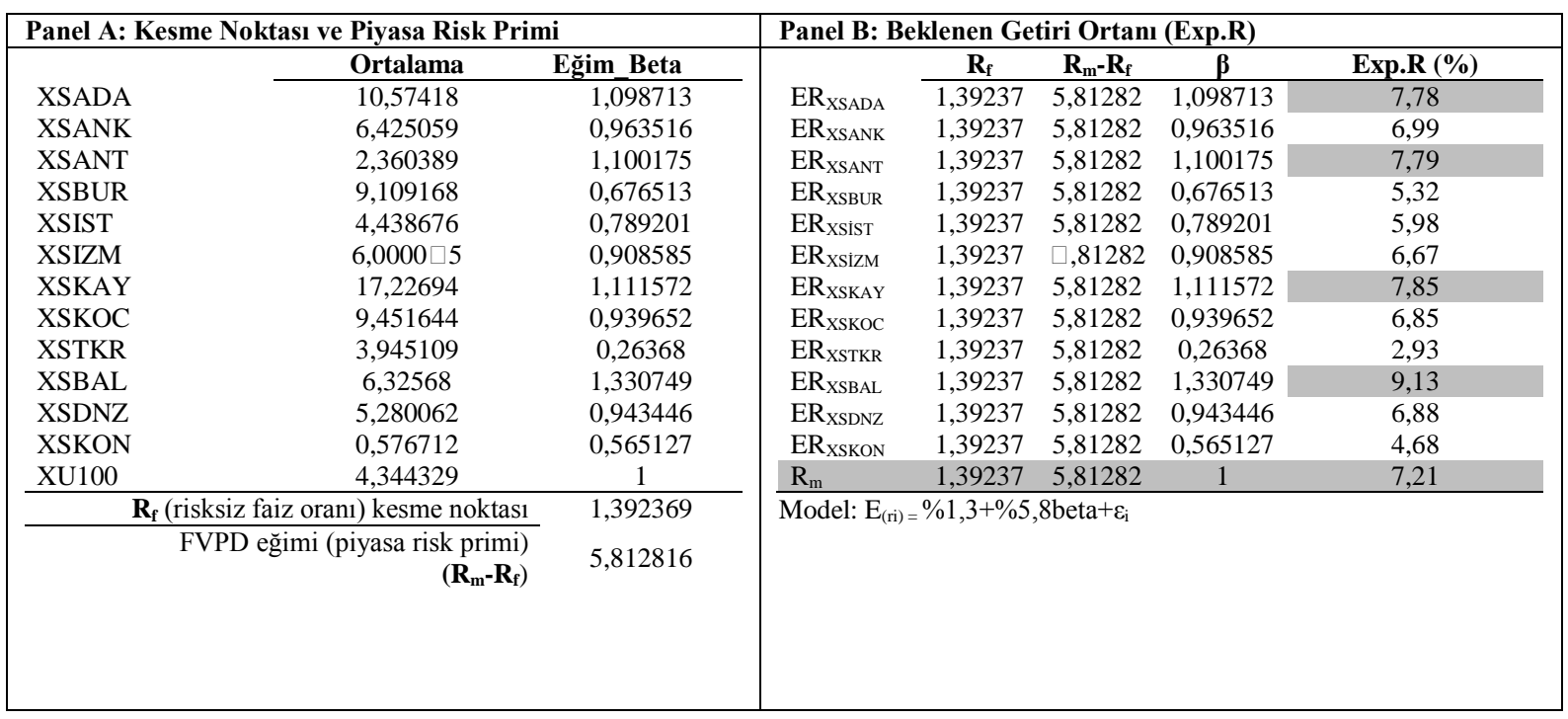

Tablo 3'ten de görüldüğü üzere Panel A'da şehir endekslerine ait ortalama getiriler ve beta değerleri dikkate alınarak kesme noktası hesaplanmıştır. Buna göre analizde kullanılacak $\mathrm{R}_{\mathrm{f}}$ değeri yaklaşık olarak \%1,39'dur. Dolayısıyla teorik olarak risksiz varlığın betasının sıfır olduğu durumda riske katlanmak istemeyen yatırımcının şehir endekslerinden kurduğu portföyden elde edeceği getiri oranı $\mathrm{R}_{\mathrm{f}}$ oranı olan \%1,39 kadar olacaktır. Bu bağlamda şehir endeksi yatırımcısının riskten kaçınma derecesini ifade eden piyasa risk primi ise $\% 5,81$ olarak hesaplanmıştır. Panel B'de, elde edilen $R_{f}$ ve piyasa risk primi dikkate alınarak

\footnotetext{
${ }^{7}$ Windows Office programına ait uygulamadır.
} 
yatırımcının ve pazar portföyünün elde edebileceği beklenen getiriler FVPD modeli kapsamında hesaplanmıştır. Buna göre pazar portföyünün betası 1 olarak kabul edildiğinden $\mathrm{R}_{\mathrm{f}}$ değeri ile piyasa risk primi toplanarak $\mathrm{R}_{\mathrm{m}} \% 7,21$ olarak bulunmuştur. Diğer bir ifadeyle şehir endekslerine yatırım yapmayan sadece pazara (BIST 100) yatırım yapan bir yatırımcının elde edebileceği getiri oranı \%7,21'dir. Model kapsamında bu şekilde hesaplanan şehir endekslerinin beklenen getiri değerlerine bakıldığında XSADA $(7,78)$, XSANT $(7,79)$, XSKAY $(7,85)$ ve XSBAL $(9,13)$ endekslerine yatırım yapan bir yatırımcının pazar portföyünden daha fazla getiri elde ettiği görülmektedir. Buna karşın diğer şehir endekslerine yatırım yapan bir yatırımcının daha düşük getiri elde edeceği görülmektedir. En yüksek beklenen getiriyi XSBAL şehir endeksi verirken, en düşük getiriyi ise XSTKR $(2,93)$ vermiştir. Tablo 4'te şehir endekslerine ait beklenen ve gerçekleşen getiriler ile bunlara ait sıralamalar özet olarak verilmiştir.

Tablo 4. Şehir Endekslerinin Beklenen ve Gerçekleşen Getirilerinin Karşılaştırılması

\begin{tabular}{|c|c|c|c|c|c|}
\hline & \multicolumn{3}{|c|}{ Beklenen Getiri* } & \multicolumn{2}{|c|}{$\begin{array}{c}\text { Gerçekleşen Getiri** } \\
\text { (GG) \% }\end{array}$} \\
\hline XSADA & 1,10 & 7,78 & 4 & 2 & 10,57 \\
\hline XSANK & 0,96 & 6,99 & 5 & 5 & 6,43 \\
\hline XSANT & 1,10 & 7,79 & 3 & 11 & 2,36 \\
\hline XSBUR & 0,68 & 5,32 & 10 & 4 & 9,11 \\
\hline XSIST & 0,79 & 5,98 & 9 & 9 & 4,44 \\
\hline XSIZM & 0,91 & 6,67 & 8 & 7 & 6,00 \\
\hline XSKAY & 1,11 & 7,85 & 2 & 1 & 17,23 \\
\hline XSKOC & 0,94 & 6,85 & 7 & 3 & 9,45 \\
\hline XSTKR & 0,26 & 2,93 & 12 & 10 & 3,95 \\
\hline XSBAL & 1,33 & 9,13 & 1 & 6 & 6,33 \\
\hline XSDNZ & 0,94 & 6,88 & 6 & 8 & 5,28 \\
\hline XSKON & 0,57 & 4,68 & 11 & 12 & 0,58 \\
\hline XU100 & 1,00 & 7,21 & - & - & 4,34 \\
\hline
\end{tabular}

Tablo 4 incelendiğinde şehir endekslerinin yatırımcısına hali hazırda sağladığı ve katlanılan riske göre elde etmesi beklenen getiriler görülmektedir. Buna göre XSANK ve XSIST şehir endekslerinin beklenen ve gerçekleşen getirilerine ait sıralama değişmemiştir (sırasıyla 5 ve 9). Sağladıkları getiriler dikkate alındığında XSKAY, riski dikkate alan beklenen getiri açısından 2. sırada iken, gerçekleşen getiri açısından 1. sırada yer almaktadır. Benzer şekilde beklenen getiri açısından XSBAL 1. sıradayken gerçekleşen getiri açısından bu sıranın değişerek 6'ya gerilediği görülmektedir. Diğer bir açıdan bakıldığında ortalama beklenen getiriye göre (XU100=7,21) XSANT, pazar portföyünden daha fazla getiri sağlarken, gerçekleşen getiriye göre pazarın altında kalmıştır $(X U 100=4,34)$. Tersi durumda XSBUR, beklenen getiri açısından pazar portföyünün altında getiri sağlarken gerçekleşen getiri açısından pazar portföyünün üstünde getiri sağlamıştır.

Teoriye göre denge fiyat düzeyinde şehir endekslerine ait getiri düzeylerinin FVPD üzerinde yer alması gerekmektedir. Şekil 2'de şehir endekslerinin gerçekleşen ve beklenen getirileri dikkate alınarak çizilmiş FVPD yer almaktadır. Şehir endekslerinin düşük veya aşırı değerlenmiş olup olmadığına yönelik araştırma bulguları aşağıda Şekil-2'de verilmiştir. 


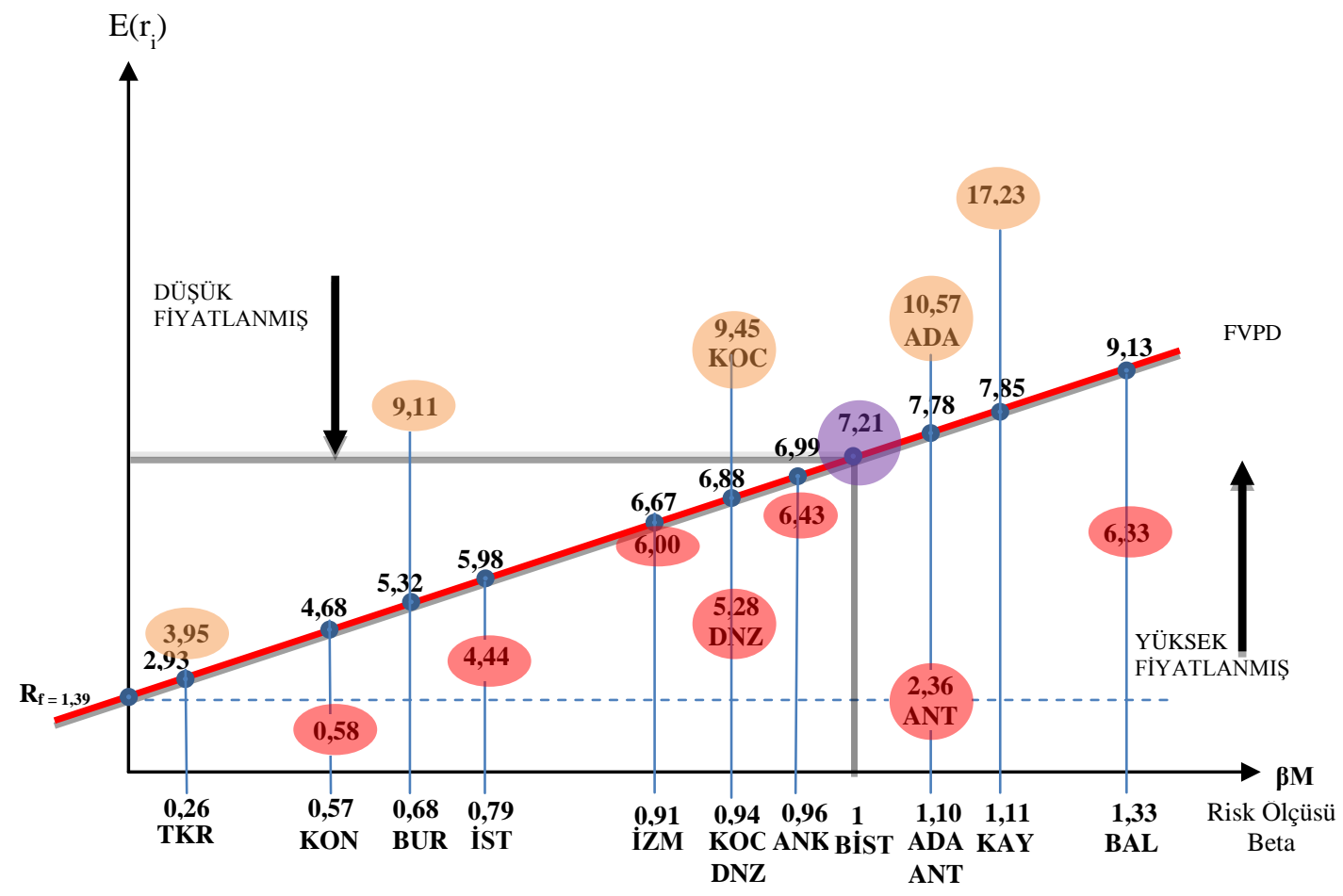

Şekil 2. Düşük ve Aşırı Değerlenmiş Şehir Endeksleri

Şehir endekslerin sahip olduğu risk ile tutarlı olan beklenen getiriyi sağlayacak şekilde piyasada fiyatının oluşması gerekir. Eğer şehir endekslerinin beklenen getirileri, gerçekleşen getirilerinden farklı olursa bu şehir endeksleri FVPD üzerinde yer almaz. Gerçekleşen getirilerin beklenen getirilerden daha yüksek veya daha düşük olması durumu, şehir endekslerinin pahalı veya ucuz olmasına işaret etmektedir (Karan, 2004: 218).

Şekil 2 incelendiğinde; şehir endekslerinin taşıdığı risk kapsamında olması gereken diğer bir ifadeyle beklenen getirileri FVPD üzerinde görünmektedir. FVPD, 1,39 olan $\mathrm{R}_{\mathrm{f}}$ sabit katsayısı ve 7,21 olan pazarın beklenen getirisi dikkate alınarak çizilmiştir. $\mathrm{Bu}$ durumda pazar portföyünün beklenen getirisi \%7,21 iken piyasa risk primi olarak bilinen diğer bir ifadeyle FVPD eğimi 5,81'dir. Dolayısıyla pazar betasından daha düşük beta değerlerine sahip olan XSTKR, XSKON, XSBUR, XSIST, XSIZZM, XSKOC, XSDNZ ve XSANK şehir endeksleri düşük riskli olarak kabul edilmektedir. Buna karşın XSADA, XSANT, XSKAY ve XSBAL ait beta değerleri 1'den büyük olduğundan daha yüksek risklidir.

Belirli bir risk düzeyinde gerçekleşen getiriler ile beklenen getiriler karşılaştırıldığında gerçekleşen getirilerin yüksek olduğu durumda finansal varlığın düşük değerlendiği kabul edilir. Bu durumda varlığın fiyatı düşük ancak getirisi yüksek düzeyde gerçekleşmiştir. Bu şartlar altında gelecek dönemde piyasada yüksek getiriye sahip olan bu varlığa talep artacak ve fiyatı da yükselecektir. Dolayısıyla fiyatlar FVPD üzerinde yükselerek dengeye gelecektir. Gerçekleşen getirilerin beklenen getirilerden düşük olduğu durumda varlığın fiyatı yüksek buna karşın getirisi düşük olarak kabul edilir. Aşırı değerlenmiş olarak kabul edilen bu varlığa talep azalarak zamanla fiyatı düşecektir. Sonuç itibariyle FVPD üzerinde dengeye düşerek 
gelecektir. Bu durumda FVPD üstünde getiri sağlayan varlıklar ucuz, altında getiri sağlayan varlıklar ise pahalı olacaktır. Finansal yatırıme bu duruma bakarak yatırım kararı verebilir.

Analiz kapsamında olan XSKAY şehir endeksinin 1,11'lik risk düzeyinde beklenen getirisi hesaplamalar sonucu 7,85 bulunmuştur. Gerçekleşen getiri düzeyi 17,23 olduğundan dolayı bu endekse yatırım yapan bir yatırımcı beklediğinden daha fazla getiri elde etmiştir. Piyasadaki diğer yatırımcılarda XSKAY şehir endeksine yatırım yaparak yüksek getiri elde etmek isteyeceğinden zamanla fiyat yükselecek ve getiri düşecektir. Bu şehir endeksi ucuz olarak kabul edilir. XSANT şehir endeksinin 1,10'luk risk düzeyinde beklenen getirisi 7,79 iken gerçekleşen getiri 2,36 düzeyinde olmuştur. Buna göre varlık aşırı değerlenmiş ve yatırımcının beklediğinden daha az getiri sağlamıştır. Zamanla talep azalarak fiyatı düşme eğiliminde olacaktır. Bu şehir endeksi pahalı olarak kabul edilir.

Araştırma kapsamında yer alan XSTKR, XSBUR, XSKOC, XSADA ve XSKAY şehir endekslerine ait gerçekleşen getiriler finansal varlık pazar doğrusunun üs kısmında yer aldığından ucuz olarak değerlendirilmiştir. Yatırımcılar bu şehir endekslerine dengeye gelinceye kadar yatırım yaparak daha fazla getiri elde edebilirler. XSKON, XSIST, XSIZM, XSDNZ, XSANK, XSANT ve XSBAL şehir endekslerine ait gerçekleşen getiriler finansal varlık pazar doğrusunun alt kısmında yer aldığından pahalı olarak değerlendirilmiştir. Yatırımcılar bu şehir endekslerine dengeye gelinceye kadar yatırım yapmamalı veya portföyünde yer alıyorsa kısa pozisyona geçmelidir.

\section{SONUÇ VE DEĞERLENDİRME}

Risk-getiri dengesinin gözetilerek aşırı veya düşük değerlenmiş olan şehir endekslerinin belirlenmesi amacıyla gerçekleştirilen bu çalışma kapsamında BIST'te işlem gören şehir endeksleri dikkate alınmıştır. Bu doğrultuda öncelikle her bir şehir endeksinin ilgili dönemde ortalama getirileri, beta ve eğim beta değerleri hesaplanmıştır. Ortalama getiriler incelendiğinde en fazla ortalama getiri sağlayan şehir endeksinin XSKAY olduğu, en düşük ortalama getiriye sahip şehir endeksinin ise XSKON olduğu görülmüştür. Bir bütün olarak incelendiğinde şehir endekslerinin büyük bir çoğunluğunun BIST 100 endeksinin ortalama getirisinden daha fazla ortalama getiri sağladığ belirlenmiştir. Eğim beta değerlerine göre ise bütün şehir endekslerinin pazar portföyüyle aynı yönde seyir izlediği, XSBAL'ın pazara en fazla, XSTKR'in ise en az tepki verdiği görülmüştür.

Şehir endekslerinin beklenen getirilerinin hesaplanabilmesi için her bir endeksin ortalama getirisi ile beta değerlerinin "kesme noktası" risksiz faiz oranı olarak alınmıştır. Ayrıca FVFD'un eğimi piyasa risk primi olarak hesaplanmıştır. Buna göre pazar portföyünün beta katsayısı dikkate alınarak şehir endeksleri yerine pazara yatırım yapan bir yatırımcının getiri oranı hesaplanmıştır. Beklenen getiri açısından XSBAL, XSKAY, XSANT ve XSADA şehir endeksleri pazar portföyünden daha yüksek getiri sağlarken, diğer şehir endeksleri pazarın altında kalmıştır. Ancak bu sıralamalar gerçekleşen getiri açısından bakıldığında değişiklik göstermiştir. Beklenen getiri açısından pazarın altında yer alan XSBUR, gerçekleşen getiri açısından pazarın üstünde getiri sağlamıştır.

Şehir endekslerinin taşıdığı risk kapsamında gerçekleşen getirilere göre XSTKR, XSBUR, XSKOC, XSADA, XSBAL beklenen getirilerden daha fazla getiri sağlamış ve FVPD'un üst kısmında yer almıştır. Dolayısıyla bu endekslerin fiyatları düşük olmasına 
rağmen getirileri yüksek olmuştur. Diğer şehir endekslerinin ise gerçekleşen getirileri beklenen getirilerinden düşük olduğu için fiyatları yüksek getirileri düşük gerçekleşmiştir. Zamanla FVPD üzerinde dengeye gelineceğinden fiyatı düşük olanların taleple birlikte fiyatı yükselecek, yüksek olanların ise fiyatı düşecektir. Dengeye gelene kadar fiyatı düşük olan endekslere yatırım yapılabilecekken, fiyatı yüksek olan endekslere yatırımdan kaçınmak yatırımcı açısından daha doğru olacaktır. Burada elde edilen bulguların şehirlerin özel durumu ile ilgili olup olmadığ 1 ölçülmemiştir.

$\mathrm{Bu}$ çalışmada geriye dönük beş y1llık periyotta günlük değerler kullanılarak beta katsayısı hesaplamaları yapılmıştır. 2012 yılında iki adet yeni şehir endeksi dahil edildiği için böyle bir sınırlama yoluna gidilmiştir. Beta katsayısına yönelik farklı hesaplama yöntemleri de dikkate alındığında hesaplamalara yönelik farklı sonuçlar elde edilebileceği açıktır. Çalışmada yapılan değerlendirmeler hesaplamalara bağlı olduğu için sonuçlara ihtiyatla yaklaşılmalıdır. Elde edilen bulgular, şehir endeksleri ile bu endeksleri oluşturan firmaların yapısı, bağlı bulunduğu sektör gibi durumları dikkate alınarak çalışmanın kapsamı genişletilebilir. Bu noktada şehir endeksleri ile o şehirlerde bulunan firmalar arasındaki ilişkiler tespit edilebilir.

Burada elde edilen sonuçlar geleceği yansıtmamaktadır. Bundan sonraki çalışmalara 1şık tutması açısından farklı hesaplama yöntemleri kullanılarak karşılaştırmalar yapılabilir. Ayrıca farklı dönemler dikkate alınarak çalışmanın sonuçları tekrarlanabilir.

\section{KAYNAKLAR}

Akbulaev, Nurhodja; Aliyeva, Besti; Ahmedova, Xayale (2016), "Finansal Varlik Fiyatlama Modeli", Süleyman Demirel Üniversitesi Sosyal Bilimler Enstitüsü Dergisi(CİEP Özel Sayıs1), 200-214.

Akel, Veli (2014), "Bist Şehir Endeksleri İle Kayseri Şehir Endeksinde Yer Alan Şirketlerin Borsa Performanslarının Karşılaştırmalı Analizi”, 3. Kayseri Ekonomisi Sempozyumu, 46-68.

Altay, Erdinç (2004), Sermaye Piyasası'nda Varlık Fiyatlama Teorileri: Sermaye Piyasası Teorisi ve Arbitraj Fiyatlama Teorisi, Derin Yayınevi, İstanbul.

Altay, Erdinç; Satman, M. Hakan (2005), “Stock Market Forecasting: Artificial Neural Network and Linear Regression Comparison in an Emerging Market”, Journal of Financial Management and Analysis, Cilt: 18, Say1: 2, 18-33.

Aşkın, Öyküm Esra; Büyüklü, Ali Hakan (2014), “BİST Şehir Endeksleri İçin Takvim Anomalilerinin Simetrik ve Asimetrik GARCH Modelleri ile Test Edilmesi”, İktisat İşletme ve Finans, Cilt: 29, Sayı: 336, 59-82.

Aydemir, Aysel (2017), Endeks Nedir? Başlıca Önemli Endeksler https://www.gcmforex.com/egitim/makale-arsivi/endeks-nedir-baslica-onemli-endeksler/, Erişim Tarihi: 21.02.2018. 
Bayraktar, Ahmet (2012), “Endeks Etkisi: İMKB Uygulaması”, Aksaray Üniversitesi İktisadi ve İdari Bilimler Fakültesi Dergisi, Cilt: 4, Sayı: 2, 89-110.

Bayramoğlu, Mehmet Fatih; Pekkaya, Mehmet (2010), “İMKB Tarafindan Hesaplanan Endekslerde Yeni Gelişmeler ve İMKB Şehir Endeksleri”, Muhasebe ve Finansman Dergisi, Sayı: 45, 200-215.

Beirne, John, Caporale; Guglielmo Maria; Schulze-Ghattas, Marianne; Spagnolo, Nicola (2009), "Volatility Spillovers and Contagion from Mature to Emerging Stock Markets", Brunel University Department of Economics and Finance Working Paper Series, No. 09-05.

BİAŞ, Borsa İstanbul A.Ş. (2013), Borsa İstanbul 432 Numaralı Genelge Bist Pay Endeksleri Temel Kuralları, İstanbul.

Boyacıŏlu, Melek Acar; Avc1, Derya (2010), "An Adaptive Network-Based Fuzzy Inference System (ANFIS) for the Prediction of Stock Market Return: The Case of the İstanbul Stock Exchange”, Expert System with Applications, Sayı: 37, 7908-7912.

Çakır, Zahide (2016), "Şehir Endekslerinin Finansal Performanslarının Ölçülmesi ve Değerlendirilmesi”, Hitit Üniversitesi Sosyal Bilimler Enstitüsü, Yayınlanmamış Yüksek Lisans Tezi, Çorum.

Diler, Ali İhsan (2003), "İMKB Ulusal 100 Endeksinin Yönünün Yapay Sinir Ağları Hata Geriye Yayma Yöntemi ile Tahmin Edilmesi”, İMKB Dergisi, Cilt: 7, Sayı: 25-26, 6581. Trabzon.

Dağlı, Hüseyin (2004), Sermaye Piyasası ve Portföy Analizi, Derya Kitabevi,

Fontanills, George A. (2005), The Options Course, Second Edition, New Jersey, John Wiley and Sons Inc., USA. İstanbul.

Gürsoy, Cudi Tuncer (2012), Finansal Yönetim İlkeleri, 2. Bask1, Beta Yayınları, Ankara.

Karan, Mehmet Baha (2011), Yatırım Analizi ve Portföy Yönetimi, Gazi Kitabevi,

Kim, Kyoung-jae (2003), "Financial Time Series Forecasting Using Support Vector Machines”, Neurocomputing, Volume: 55, 307-319.

Korkmaz, Turhan; Pekkaya, Mehmet (2005), Excel Uygulamalı Finans Matematiği, Ekin Kitabevi, Bursa.

Liu, Y. Angele; Pan, Ming-Shiun, (1997), "Mean and Volatility Spillover Effects in the U.S. and Pasific-Basin Stock Markets”, Multinational Finance Journal, Volume: 1, No. 1, 47-62. 
Mazgit, İsmail, (2013), "Endeks Kapsamında Olmanın Hisse Senedi Getirilerine Etkisi: BİST Temettü 25 Endeksi Üzerine Bir Uygulama”, Sosyoekonomi, Cilt: 20, Sayı: 20, 225-264.

Masih, Abul, M.M.; Masih, Rumi, (2001), "Long and Short Term Dynamic Casual Transmission amongst International Stock Markets”, Journal of International Money and Finance, No. 20, 563-587.

Özdemir, A. Kerem; Tolun, Seda; Demirci, Ebru (2011), “Endeks Getirisi Yönünün İkili Sınıflandırma Yöntemiyle Tahmin Edilmesi: İMKB-100 Endeksi Örneğgi”, Niğde Üniversitesi İIBBF Dergisi, Cilt: 4, Sayı: 2, 45-59.

Worthington, Andrew; Higgs, Helen (2004), "Transmission of Equity Returns and Volatility in Asian Developed and Emerging Markets: a Multivariate GARCH Analysis”, International Journal of Finance \& Economics, Volume: 9, No. 1, 71-80. 
EK 1. ŞEHİR ENDEKSLERİ KAPSAMINDA OLAN BİST ŞİRKETLERİ

\begin{tabular}{|c|c|c|c|c|c|c|c|}
\hline \multicolumn{7}{|c|}{ BIST ŞEHIR ENDEKSLERİ } & \multirow{3}{*}{$\begin{array}{c}\text { Toplam } \\
6 \text { şirket }\end{array}$} \\
\hline \multicolumn{7}{|c|}{ BİST ADANA ENDEKSI } & \\
\hline ADANA & ADNAC & ADBGR & BLCYT & BOSSA & SASA & & \\
\hline \multicolumn{7}{|c|}{ BIST ANKARA ENDEKSI } & \multirow{4}{*}{15 şirket } \\
\hline ALCTL & ASELS & BEYAZ & EMKEL & FONET & IPEKE & KAREL & \\
\hline KOZAA & LKMNH & OSTIM & SAMAT & TTKOM & TTRAK & ULUSE & \\
\hline ULKER & & & & & & & \\
\hline \multicolumn{7}{|c|}{ BİST ANTALYA ENDEKSI } & \multirow{2}{*}{5 şirket } \\
\hline MAALT & MARTI & TEKTU & ULAS & UTPYA & & & \\
\hline \multicolumn{7}{|c|}{ BİST BALIKESIR ENDEKSI } & \multirow[b]{2}{*}{4 şirket } \\
\hline BAGFS & BNTAS & BANVT & KRSTL & & & & \\
\hline \multicolumn{7}{|c|}{ BİST BURSA ENDEKSI } & \multirow{4}{*}{17 şirket } \\
\hline BRMEN & BFREN & BURCE & BUCIM & COMDO & CEMTS & KARSN & \\
\hline KERVT & MERKO & PENGD & SANKO & SONME & SNPAM & TATGD & \\
\hline TOASO & PRKAB & ZOREN & & & & & \\
\hline \multicolumn{7}{|c|}{ BIST DENIZLI ENDEKSİ } & \multirow{2}{*}{4 şirket } \\
\hline ACSEL & DENCM & KNFRT & MNDRS & & & & \\
\hline \multicolumn{7}{|c|}{ BİST İSTANBUL ENDEKSI } & \multirow{14}{*}{90 şirket } \\
\hline ADEL & AGHOL & AKCNS & AKGUV & AKENR & AKSEN & ALCAR & \\
\hline ALARK & AEFES & ANELE & ARCLK & ARENA & ARMDA & ATPET & \\
\hline AVTUR & AYGAZ & BJKAS & BRSAN & BRYAT & BOYP & CCOLA & \\
\hline CLEBI & CUSAN & DAGI & DGATE & DENGE & DERIM & DESPC & \\
\hline DGZTE & DOHOL & DOAS & DURDO & ECZYT & EDIP & ECILC & \\
\hline ENJSA & ENKAI & ESCOM & FENER & FLAP & GSRAY & GLYHO & \\
\hline GOODY & GSDDE & GSDHO & GUBRF & GLRYH & SAHOL & HURGZ & \\
\hline IEYHO & IHEVA & $\begin{array}{l}\text { IHGZT } \\
\end{array}$ & IHLAS & IHYAY & INDES & INTEM & \\
\hline IZOCM & KCHOL & KRONT & KUYAS & LINK & MARKA & METUR & \\
\hline METRO & MPARK & NTHOL & NETAS & OLMIP & ORGE & PARSN & \\
\hline PGSUS & PKART & POLTK & PRZMA & RYSAS & SANAL & SELEC & \\
\hline TAVHL & TKFEN & TGSAS & TRKCM & TUCLK & TRCAS & TCELL & \\
\hline THYAO & TURGG & SISE & VERUS & YYAPI & YESIL & & \\
\hline \multicolumn{7}{|c|}{ BISTT IZZMİR ENDEKSİ } & \multirow{5}{*}{27 şirket } \\
\hline ALKA & ALYAG & AVOD & BAKAB & BTCIM & CMBTN & CMENT & \\
\hline EGEEN & EGGUB & EGPRO & EGSER & IHLGM & IZMDC & IZFAS & \\
\hline KAPLM & KATMR & KOZAL & TIRE & PSDTC & PETKM & PETUN & \\
\hline PINSU & PNSUT & SAFKR & SAYAS & TUKAS & TBORG & & \\
\hline \multicolumn{7}{|c|}{ BİST KAYSERİ ENDEKSII } & \multirow{2}{*}{6 şirket } \\
\hline AYEN & ERBOS & KRTEK & OYLUM & TMPOL & YATAS & & \\
\hline \multicolumn{7}{|c|}{ BIST KOCAELİ ENDEKSI } & \multirow{4}{*}{19 şirket } \\
\hline ASUZU & ASLAN & BRISA & CELHA & DYOBY & FMIZP & FROTO & \\
\hline HEKTS & KARTN & KENT & KORDS & LOGO & MAKTK & MRSHL & \\
\hline NUHCM & POLHO & RTALB & SARKY & TUPRS & & & \\
\hline \multicolumn{7}{|c|}{ BIST KONYA ENDEKSI } & \\
\hline BERA & ERSU & ITTFH & KONYA & TMSN & & & ogुnet \\
\hline BİST TEI & $\overline{\mathrm{DAĞG} \mathrm{EN}}$ & KSII & & & & & \\
\hline BRKSN & DEVA & YUNSA & & & & & rket \\
\hline
\end{tabular}

